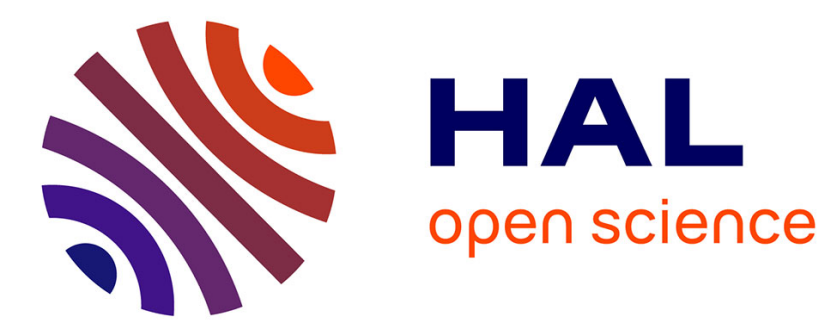

\title{
Mining bases for association rules using closed sets
}

\author{
Rafik Taouil, Nicolas Pasquier, Yves Bastide, Lotfi Lakhal
}

\section{To cite this version:}

Rafik Taouil, Nicolas Pasquier, Yves Bastide, Lotfi Lakhal. Mining bases for association rules using closed sets. ICDE'2000 International Conference, Feb 2000, San Diego, United States. pp.307. hal00467758

\section{HAL Id: hal-00467758 \\ https://hal.science/hal-00467758}

Submitted on 26 Apr 2010

HAL is a multi-disciplinary open access archive for the deposit and dissemination of scientific research documents, whether they are published or not. The documents may come from teaching and research institutions in France or abroad, or from public or private research centers.
L'archive ouverte pluridisciplinaire HAL, est destinée au dépôt et à la diffusion de documents scientifiques de niveau recherche, publiés ou non, émanant des établissements d'enseignement et de recherche français ou étrangers, des laboratoires publics ou privés. 


\title{
Mining Bases for Association Rules Using Closed Sets
}

\author{
Rafik Taouil Nicolas Pasquier Yves Bastide Lotfi Lakhal \\ LIMOS - Université Clermont-Ferrand II - 24 av. des Landais, 63177 Aubière France \\ \{pasquier,bastide,taouil,lakhal\}@libd2.univ-bpclermont.fr
}

\begin{abstract}
We address the problem of the usefulness and the relevance of the set of discovered association rules. Using the frequent closed itemset groundwork, we propose to generate bases for association rules, that are non-redundant generating sets for all association rules.
\end{abstract}

\section{Introduction}

Association rules are conditional implications between frequent itemsets. The problem of the usefulness and the relevance of the set of discovered association rules is related to the huge number of rules extracted and the presence of many redundancies among these rules for many datasets. We address this important problem using the Galois connection framework and we show that we can generate bases for association rules using the frequent closed itemsets extracted by the Close [4] or the A-Close [5] algorithms.

\section{Galois connection framework}

The association rule extraction is performed from a data mining context that is a triplet $\mathcal{D}=(\mathcal{O}, \mathcal{I}, \mathcal{R})$, where $\mathcal{O}$ and $\mathcal{I}$ are finite sets of objects and items respectively, and $\mathcal{R} \subseteq \mathcal{O} \times \mathcal{I}$ is a binary relation. Each couple $(o, i) \in \mathcal{R}$ denotes the fact that the object $o \in \mathcal{O}$ is related to the item $i \in \mathcal{I}$. The closure operator $h$ of the Galois connection [1] is the composition of the application $f$, that associates with $O \subseteq \mathcal{O}$ the items common to all objects $o \in O$, and the application $g$, that associates with an itemset $I \subseteq \mathcal{I}$ the objects related to all items $i \in I$. The closure operator $h=f \circ g$ associates with $I$ the maximal set of items common to all the objects containing $I$, i.e. the intersection of these objects. Using this closure operator, we define the frequent closed itemsets that constitute a minimal non-redundant generating set for all frequent itemsets and their support, and thus for all association rules, their support and their confidence. This property comes from the fact that the support of a frequent itemset is equal to the support of its closure and that the maximal frequent itemsets are maximal frequent closed itemsets [4, 5].

Definition 1 (Frequent closed itemsets) A frequent itemset $I$ is a frequent closed itemset iff $h(I)=I$. The smallest (minimal) closed itemset containing an itemset $I$ is $h(I)$, i.e. the closure of $I$. We denote $F C$ the set of frequent closed itemsets in $\mathcal{D}$.

\section{Bases for association rules}

We adapt the Duquenne-Guigues basis for global implications $[2,1]$ and the Luxenburger basis for partial implications [3] to the exact association rules (100\% confidence rules) and the approximate association rules respectively.

Theorem 1 (Duquenne-Guigues basis) A frequent pseudo-closed itemset is a frequent itemset that is not closed and that contains the closures of all its subsets that are frequent pseudo-closed itemsets. Let FP be the set of frequent pseudo-closed itemsets in $\mathcal{D}$. The Duquenne-Guigues basis for exact association rules contains all rules of the form $I_{1} \rightarrow\left(I_{2} \backslash I_{1}\right)$ for $I_{1} \in F P, I_{2} \in F C$ and $h\left(I_{1}\right)=I_{2}$.

Theorem 2 (Luxenburger basis) The Luxenburger basis for approximate association rules contains all rules of the form $I_{1} \rightarrow\left(I_{2} \backslash I_{1}\right)$ for $I_{1}, I_{2} \in F C$ and $I_{1} \subset I_{2}$. The transitive reduction of this basis, i.e. for $I_{1} \subset I_{2}$ and $\nexists I_{3} \in F C$ such as $I_{1} \subset I_{3} \subset I_{2}$, is also a basis for all approximate association rules.

All approximate association rules, their support and their confidence can be deduced from the Luxenburger basis, or its reduction, and all exact association rules can be deduced from the Duquenne-Guigues basis. They are minimal non redundant sets of association rules.

\section{References}

[1] B. Ganter and R. Wille, Formal Concept Analysis: Mathematical foundations, Springer, 1999.

[2] V. Duquenne and J.-L. Guigues, "Famille minimale d'implications informatives résultant d'un tableau de données binaires", Math. et Sci. Hum., 24(95):5-18, 1986.

[3] M. Luxenburger, "Implications partielles dans un contexte", Math., Inf. et Sci. Hum., 29(113):35-55, 1991.

[4] N. Pasquier, Y. Bastide, R. Taouil and L. Lakhal, "Efficient mining of association rules using closed itemset lattices", Information Systems, 24(1):25-46, 1999.

[5] N. Pasquier, Y. Bastide, R. Taouil and L. Lakhal, "Discovering frequent closed itemsets for association rules", Proc. ICDT Conf., pp 398-416, January 1999. 